\title{
Study on Agricultural Synthesis Productivity in the Prefecture-Level Cities of Sichuan Province Based on Grey Relation Analysis
}

\author{
Ruiqi SUN, Guozhu HE* \\ Sichuan Agricultural University, Dujiangyan, Sichuan,611830, China \\ Email: heguozhu@sicau.edu.cn

\begin{abstract}
The level of agricultural production is a key element in rural regional planning, and agricultural synthesis productivity is considered as an important factor to evaluate the agricultural productivity of a certain region. Applying the Grey Relation Analysis method, this paper evaluates and ranks the agricultural synthesis productivity in 21 prefecture-level cities of Sichuan Province. The result shows that the agricultural synthesis productivity in the mid-east region is obviously higher than that in the north-west and south-west regions, which results from the insufficient agricultural comprehensive input-output. Based on the above analysis, this paper puts forward some targeted improvement suggestions.
\end{abstract}

Keywords: grey relation, agricultural synthesis productivity, prefecture-level cities

\section{INTRODUCTION}

Chinese scholars' research on total agricultural productivity is mainly concentrated at the macro level, and the total output value of agriculture, forestry, animal husbandry and fishery (or total agricultural output value) is used as a specific indicator to measure the level of total agricultural output. $\mathrm{Yu}$ Yan broke through this limitation, using factor analysis method, using systematic and multi-factor analysis method to analyze the influencing factors of agricultural comprehensive productivity, and empirically studying the influence of various production factors on agricultural comprehensive production capacity[1]. Yan Chaode and others, took Henan province as an example, adopted gray relative analysis method to select 11 variables from the perspective of agricultural investment to analyze specific factors affecting overall agricultural productivity, and they also proposed that the agricultural fund had become the most important factor affecting the overall agricultural productivity in Henan province[2]. Judging from existing documents, there are no relevant documents on researches of overall agricultural productivity in Sichuan province, and previous researches were centered on agricultural sustainable development, characteristic agriculture, and agricultural production efficiency[3] Besides, those researches conduct analysis from qualitative point of view and from such aspects as agricultural resource utilization, and researches on overall agricultural productivity of various prefecture-level cities in the province from quantitative point of view are relatively less.

The overall agricultural productivity is a vital factor in agricultural development as it reveals the comprehensive input and output capacity of various factors during the process of agricultural production. This paper, with a view to natural resources, actual ecological environment, as well as regional development characteristics of Sichuan province, makes quantitative analysis of overall agricultural productivity conditions of various prefecture-level cities of Sichuan province in order to provide a basis for relevant departments of the government in making industrial development policy and regional development plan.

\section{GRAY RELATIVE ANALYSIS METHOD}

\subsection{Connotation of Gray Relative Analysis Method}

Gray relative analysis is one of the analysis methods of gray system theory, and its basic idea is to judge the relational degree between various factors according to similarity between curves. Generally speaking, the more similar the geometric shapes of curves are, the more similar their change tendencies are and the closer their relational degrees are, and vice versa. It has neither particular requirements for sample size nor demands for typical distribution rules in analysis; besides, there will be no such situation of inconsistent results between quantitative analysis and qualitative analysis due to small amount of calculations. Therefore, the method can be widely applied [4].

Only a part of indicators can be selected to make analysis during the evaluation as the overall agricultural productivity can be affected by many factors which have a complicated relationship and as it is hard to obtain certain data. It is inevitable that the evaluation may have "gray" feature as information obtained may be incomplete. Thus, 


\section{EVALUATION OF OVERALL AGRICULTURAL PRODUCTIVITY OF PREFECTURE-LEVEL CITIES OF SICHUAN PROVINCE}

\subsection{Calculation Principle of Gray Relative Analysis Method}

\subsubsection{Determining Reference Sequence and Comparison Sequence}

Sequence that can reflect features of system behaviors is called reference sequence or main sequence $\mathrm{x} 0(\mathrm{k})$. Data sequence that is composed of factors affecting system behaviors is called comparison sequence or sub-sequence $\mathrm{xi}(\mathrm{k}),(\mathrm{k}=1,2,3, \ldots \ldots .7 ; \mathrm{i}=1,2,3, \ldots . ., 21)$.

\subsubsection{Absolute Difference of Sequence}

Formula of Absolute Difference of Sequence:

$\Delta_{0 i}(k)=\left|x_{0}(k)-x_{i}(k)\right| \quad(k=1,2,3, \cdots \cdots, n)$

Secondary Minimum Difference is:

$$
\Delta_{\min }=\min _{i} \min _{k}\left|x_{0}(k)-x_{i}(k)\right|
$$

Secondary Maximum Difference is:

$\Delta_{\max }=\max _{i} \max _{k}\left|x_{0}(k)-x_{i}(k)\right|$

\subsubsection{Calculation of Correlation Coefficient}

Given the main sequence of data change is $\mathrm{x} 0(\mathrm{k})$, and the subsequence is $x i(k)$, the formula of correlation coefficient $\zeta \mathrm{i}(\mathrm{k})$ of $\mathrm{x} 0(\mathrm{k})$ and $\mathrm{xi}(\mathrm{k})$ is:

$$
\zeta_{i}(k)=\frac{\Delta_{\min }+\rho \Delta_{\max }}{\Delta_{i}(k)+\rho \Delta_{\text {max }}}
$$

In the above formula, $\Delta \mathrm{i}(\mathrm{k})$ is the absolute difference of the $k$ th evaluation factor and reference sequence; $\Delta \max$ is the maximum value among absolute differences; $\Delta \min$ is the minimum value among absolute differences; $\rho$ is resolution ratio $(\rho \in[0,1])$ and is usually 0.5 according to international practice.

\subsubsection{Calculation of Relational Degree}

The formula is:

$$
r_{i}=\frac{1}{N} \sum_{k=1}^{N} \xi_{i}(k)
$$

In the formula, ri is the relational degree of sub-sequence and main sequence, $\mathrm{N}$ is the number of evaluation factors, and $\zeta \mathrm{i}(\mathrm{k})$ is the correlation coefficient.

\subsection{Indicator Selection}

Following the principle of a systematic, comprehensive, scientific, predominant, and operable evaluation with a reference to relevant documents[5], the two categories of indicators, that is, agricultural input and agricultural output, are selected for statistic analysis of data in 21 cities of Sichuan province in 2017. The agricultural input indicators include number of employees in farming, forestry, husbandry and fishing industries, total power of agricultural machinery, applying quantity of agricultural fertilizer, as well as electricity for rural uses. The agricultural output indicators include grain production, total yield of economic crop, total value of farming, forestry, husbandry and fishing industries output. The 21 cities of Sichuan province can be seen as a gray system and each city as a comparison sequence of this system, and then a "reference indicator" is constructed and the sequence composed of maximum performance indicator values will be the reference sequence $\mathrm{X} 0$ [5]. The seven factors affecting overall agricultural productivity including number of employees in farming, forestry, husbandry and fishing industries, total power of agricultural machinery, applying quantity of agricultural fertilizer, electricity for rural uses, grain production, total yield of economic crop, as well as total value of farming, forestry, husbandry and fishing industries output can constitute a comparison sequence $(x i(1), x i(2) 、 \ldots . . x i(k))$.

\subsection{Descriptive Statistical Analysis of Indicators}

The data is from 2018 Sichuan Province Statistical Yearbook, including number of employees in farming, forestry, husbandry and fishing industries, total power of agricultural machinery such as farming, transportation, and harvest machinery, applying quantity of agricultural fertilizer such as compound, potash, nitrogenous, phosphate fertilizers, electricity for rural uses like electromechanical irrigation, agricultural products and by-products processing, and village official businesses, production of grains like rice, wheat and corn, total yield of economic crops such as cotton, oil plants, and bast fibre crops, as well as total value of farming, forestry, husbandry and fishing industries output including output value of farming, forestry, animal husbandry, fishing industries and their relevant service sectors. First of all, a descriptive statistical analysis of various indicators is conducted (see also Table 1). 
Table 1 Descriptive Statistical Analysis

\begin{tabular}{|c|c|c|c|c|c|}
\hline Indicator & Average & Standard Deviation & Variance & Minimal Value & Maximum Value \\
\hline 1 & 99.20 & 44.49 & 1979.43 & 21.85 & 197.28 \\
\hline 2 & 150.24 & 58.38 & 3408.78 & 56.41 & 288.16 \\
\hline 3 & 11.81 & 6.36 & 40.44 & 0.29 & 23.33 \\
\hline 4 & 6.75 & 6.77 & 45.83 & 0.87 & 31.59 \\
\hline 5 & 5079.1 & 896.78 & 804217.69 & 2824.00 & 6435.00 \\
\hline 6 & 13.16 & 11.21 & 125.69 & 0.32 & 35.52 \\
\hline 7 & 193.66 & 107.92 & 11647.0 & 36.47 & 470.19 \\
\hline
\end{tabular}

The above data is from 2018 Sichuan Province Statistical Yearbook. 1=number of employees in farming, forestry, husbandry and fishing industries (ten thousand), $2=$ total power of agricultural machinery (ten thousand kilowatt), $3=$ applying quantity of agricultural

fertilizer (ten thousand ton), 4=electricity for rural uses (one hundred million kilowatt-hour), 5=grain production per unit

(kilogram/hectare), 6=total yield of economic crops (ten thousand ton), 7=total value of farming, forestry, husbandry and fishing industries output (one hundred million yuan).

As can be seen from the above table, the average number of employees in farming, forestry, husbandry and fishing industries of those 21 prefecture-level cities is 992,000, with Panzhihua city having the least number of employees $(218,500)$ and Liangshan Yi autonomous region having the largest number $(1,972,800)$. The average power of agricultural machinery is 1,502,400 kilowatts, with Panzhihua city having the least share $(564,100$ kilowatts $)$ and Chengdu city having the largest share $(2,881,600$ kilowatts). The average applying quantity of agricultural fertilizer is 118,100 tons, with the Ganzi Tibetan autonomous prefecture having the least (2,900 tons) and Nanchong city having the largest (233,300 tons). The average electricity for rural uses is 675 million kilowatt-hour, with Ganzi Tibetan autonomous prefecture having the least ( 87 million kilowatts-hour) and Chengdu city having the largest $(3,159,000,000$ kilowatts-hour). The average grain production per unit is 5,079.1 kilograms/hectare, with Ganzi Tibetan autonomous prefecture having the least (2,824 kilograms/hectare) and Deyang city having the largest (6,435 kilograms/hectare). The average total yield of economic crop is 131,600 tons, with Panzhihua city having the least (3,200 tons) and
Nanchong city having the largest (355,200 tons). The average total value of farming, forestry, husbandry and fishing industries output is 19,366,000,000 yuan, with Aba Tibetan autonomous prefecture having the least $(3,647,000,000$ yuan) and Chengdu city having the most (47,019,000,000 yuan).

\subsection{Correlation Coefficient Concerning Evaluation of Overall Agricultural Productivity of Various Prefecture-level Cities in Sichuan}

By applying gray relative analysis method and dimensionless method to indicators selected, the data after normalization processing is put into the formula to get the difference (absolute value) of various sub-data sequence and main data sequence, the absolute difference of various corresponding points of $\mathrm{x} 0$ and $\mathrm{xi}$, as well as the result that the minimum difference $\Delta \min =0$ and that the maximum difference $\Delta \max =217.2756$.

The correlation coefficient is solved by putting the above results to the formula (given that $\rho=0.5$ ) (see also Table 2).

Table 2 Correlation Coefficient

\begin{tabular}{|c|c|c|c|c|c|c|c|c|}
\hline Sequence & City & 1 & 2 & 3 & 4 & 5 & 6 & 7 \\
\hline $\mathrm{X}_{1}$ & Chengdu city & 1 & 0.9961 & 1.0001 & 0.9996 & 0.9350 & 1.0001 & 0.9936 \\
\hline $\mathrm{X}_{2}$ & Zigong city & 1 & 1.0031 & 1.0000 & 1.0010 & 0.7012 & 1.0010 & 1.0048 \\
\hline $\mathrm{X}_{3}$ & Panzhihua city & 1 & 0.9898 & 0.9998 & 1.0008 & 0.3333 & 1.0015 & 1.0066 \\
\hline $\mathrm{X}_{4}$ & Luzhou city & 1 & 1.0024 & 1.0003 & 1.0011 & 0.8854 & 1.0014 & 1.0079 \\
\hline $\mathrm{X}_{5}$ & Deyang city & 1 & 0.9971 & 0.9990 & 0.9996 & 0.7306 & 0.9998 & 0.9957 \\
\hline $\mathrm{X}_{6}$ & Mianyang city & 1 & 0.9951 & 0.9994 & 1.0007 & 0.8865 & 0.9992 & 1.0000 \\
\hline $\mathrm{X}_{7}$ & Guangyuan city & 1 & 0.9905 & 0.9999 & 1.0012 & 0.7825 & 0.9997 & 1.0081 \\
\hline $\mathrm{X}_{8}$ & Suining city & 1 & 0.9998 & 0.9991 & 1.0011 & 0.7057 & 0.9997 & 0.9974 \\
\hline $\mathrm{X}_{9}$ & Neijiang city & 1 & 0.9998 & 0.9998 & 1.0006 & 0.7997 & 1.0007 & 1.0012 \\
\hline $\mathrm{x}_{10}$ & Leshan city & 1 & 0.9971 & 1.0002 & 1.0007 & 0.8533 & 1.0010 & 1.0052 \\
\hline $\mathrm{x}_{11}$ & Nanchong city & 1 & 0.9965 & 0.9990 & 1.0010 & 0.8339 & 0.9985 & 0.9922 \\
\hline $\mathrm{x}_{12}$ & Meishan city & 1 & 0.9968 & 0.9998 & 1.0009 & 0.8242 & 1.0007 & 1.0063 \\
\hline $\mathrm{x}_{13}$ & Yibin city & 1 & 1.0033 & 1.0005 & 1.0010 & 0.9694 & 1.0012 & 1.0089 \\
\hline $\mathrm{x}_{14}$ & Guang'an city & 1 & 1.0035 & 1.0003 & 1.0012 & 0.8967 & 1.0007 & 1.0084 \\
\hline $\mathrm{x}_{15}$ & Dazhou city & 1 & 0.5532 & 0.3718 & 1.0011 & 0.5177 & 0.9997 & 1.0040 \\
\hline
\end{tabular}




\begin{tabular}{|c|c|c|c|c|c|c|c|c|}
\hline $\mathrm{X}_{16}$ & Ya'an city & 1 & 0.9872 & 1.0001 & 1.0007 & 0.6299 & 1.0010 & 1.0047 \\
\hline $\mathrm{X}_{17}$ & Bazhong city & 1 & 1.0034 & 1.0000 & 1.0013 & 0.8793 & 1.0006 & 1.0111 \\
\hline $\mathrm{X}_{18}$ & Ziyang city & 1 & 1.0004 & 1.0003 & 1.0010 & 0.9322 & 0.9999 & 1.0001 \\
\hline $\mathrm{X}_{19}$ & Aba & 1 & 0.9951 & 1.0008 & 1.0010 & 0.6339 & 1.0015 & 1.0117 \\
\hline $\mathrm{X}_{20}$ & Ganzi & 1 & 0.9996 & 1.0010 & 1.0013 & 0.8096 & 1.0015 & 1.0151 \\
\hline $\mathrm{X}_{21}$ & Liangshan & 1 & 0.8233 & 0.4578 & 1.0012 & 1.1073 & 1.0015 & 1.0088 \\
\hline
\end{tabular}

\subsection{Sequencing of Overall Agricultural Productivity of Prefecture-level Cities of Sichuan Province}

The relational degree can be solved by using the formula and then various cities can be sequenced according to the relational degrees (see also Table 3 ).

Table 3 Sequencing of Relational Degrees of Various Prefecture-level Cities

\begin{tabular}{|c|c|c|c|}
\hline Bit Sequence & City Name & Sequence & Relational Degree \\
\hline 1 & Yibin city & $\mathrm{X}_{13}$ & 0.9977 \\
\hline 2 & Ziyang city & $\mathrm{x}_{18}$ & 0.9906 \\
\hline 3 & Chengdu city & $\mathrm{x}_{1}$ & 0.9892 \\
\hline 4 & Luzhou city & $\mathrm{X}_{4}$ & 0.9855 \\
\hline 5 & Bazhong city & $\mathrm{x}_{17}$ & 0.9851 \\
\hline 6 & Mianyang city & $\mathrm{X}_{6}$ & 0.9830 \\
\hline 7 & Leshan city & $\mathrm{X}_{10}$ & 0.9796 \\
\hline 8 & Ganzi Tibetan autonomous prefecture & $\mathrm{x} 20$ & 0.9755 \\
\hline 9 & Meishan city & $\mathrm{x}_{12}$ & 0.9755 \\
\hline 10 & Nanchong city & $\mathrm{X}_{11}$ & 0.9744 \\
\hline 11 & Neijiang city & $\mathrm{X}_{9}$ & 0.9717 \\
\hline 12 & Guangyuan city & $\mathrm{x}_{7}$ & 0.9688 \\
\hline 13 & Deyang city & $\mathrm{X}_{5}$ & 0.9603 \\
\hline 14 & Zigong city & $\mathrm{X}_{2}$ & 0.9587 \\
\hline 15 & Suining city & $\mathrm{X}_{8}$ & 0.9575 \\
\hline 16 & Aba Tibetan autonomous prefecture & $\mathbf{X}_{19}$ & 0.9492 \\
\hline 17 & Ya'an city & $\mathrm{X}_{16}$ & 0.9462 \\
\hline 18 & Liangshan Yi autonomous region & $\mathrm{x} 22_{1}$ & 0.9143 \\
\hline 19 & Panzhihua city & $\mathrm{X}_{3}$ & 0.9046 \\
\hline 20 & Guang'an city & $\mathrm{X}_{14}$ & 0.8444 \\
\hline 21 & Dazhou city & $\mathrm{X}_{15}$ & 0.7782 \\
\hline
\end{tabular}

\section{RESULTS AND DISCUSSION}

Yibin, Ziyang and Chengdu in the top three of the list have a relatively high relational degree. From the perspective of natural conditions, those three cities are located at the plain area and were known as "the land of abundance" in ancient days; besides, they enjoy fertile farmlands which is beneficial to mechanized and large-scale production in order to generate high agricultural benefits. From the perspective of transportation convenience, Overall speaking, those three cities are all in the plain area with convenient transportation. And Chengdu is the transportation hub of the whole southwest region. From the perspective of location, this area is close to Chongqing which is a special administrative region with developed economy and large economic radiation effect. Thus, the area can better introduce advanced technology and management concept, and it has obvious advantages in agricultural resources to help improve the agricultural productivity. From the perspective of agricultural input, this area consumes a large amount of agricultural fertilizer to keep better soil fertility and increase agricultural output. In addition, the electricity consumption in rural areas of those three regions also top the list. It is obvious that the power grid facilities are complete there and that the government injects more in rural infrastructure, which lays a firm foundation for agricultural modernization. Besides, those three regions have relatively powerful economic 
strength as the average total power of agricultural machinery of the three regions stand at over two million kilowatts with that of Chengdu reaching 2,880,000 kilowatts to top the list of the entire province. The secondary industry will nurture the primary industry and they will supplement each other. From the perspective of agricultural output, both the grain production and total yield of economic crops are above the average level of the province. In particular, the total output of farming, forestry, husbandry and fishing industries of Chengdu city in 2010 is 47.019 billion yuan, ranking first in the entire province and promoting the development of agricultural productivity.

The relational degrees of Dazhou, Guang'an, Panzhihua, Liangshan, Ya'an and Aba are at the back of the list, which has certain bearing on limited agricultural resources of these cities. From the perspective of natural conditions, Dazhou, and Guang'an are located in the east of Sichuan and are in the hilly border region of Sichuan Basin; while the Liangshan prefecture, Ya'an and Aba prefecture are all situated in the plateau mountain areas in west and south of Sichuan with less fertile farmlands and more individual operations to make it hard for large-scale production. From the perspective of transportation convenience, this area has more plateaus and mountains, as well as incomplete means of transportation and less smooth routes, which makes it difficult to circulate resources and exchange information among various regions. From the perspective of location, this area, compared to middle and east regions of Sichuan, is close to the Yunnan-Guizhou plateau and Qinghai-Tibet plateau and has backward economic conditions and small economic radiation effects. From the perspective of agricultural input, the applying amount of agricultural fertilizer of Aba prefecture is below 10,000 tons which is obviously less than that of other regions. The soil in the area is lack of fertility to affect production of agricultural products.

\section{CONCLUSION AND SUGGESTION}

\subsection{Conclusion}

In general, all regions in Sichuan are faced with problems such as low efficiency of regional resource allocation and low level isomorphism of regional industries. With the gray relative analysis method, the ranking of various cities can be seen clearly in definite quantity. On the whole, the middle and east regions of Sichuan province have relatively developed overall agricultural productivity; in particular, the total power of agricultural machinery, the electricity for rural uses, and the total value of farming, forestry, husbandry, and fishing industries all top the list of the entire province and those regions enjoy an obvious advantages in terms of applying amount of chemical fertilizer, grain production, as well as total yield of economic crop. However, the hilly border region of Sichuan basin as well as northwest and southwest regions of Sichuan have relatively low agricultural productivity, and lag behind other regions in terms of total power of agricultural machinery, applying amount of fertilizer, electricity for rural uses, grain production, total yield of economic crops, as well as total value of farming, forestry, husbandry, and fishing industries.

\subsection{Suggestion}

Judging from the evaluation results, there is a big regional difference in the overall agricultural productivity in Sichuan province. As a result, the province must take measures to plan urban and rural development as a whole, and promote economic coordination from the perspective of the region as a whole, so as to build a well-off society in an all-round way. Besides, the improvement of agricultural productivity in the northwest and southwest regions of Sichuan province will be difficult in and key to the agricultural development during the "12th five-year plan" period, and those regions should not be a hindrance to the rapid economic development of the province. Therefore, it is essential to, on the basis of further enhancing the overall agricultural productivity of the province, exert efforts to support the northwest and southwest regions in policy, funds, and technology as well as boosting leapfrog development from traditional agriculture to modern agriculture in a comprehensive and effective way. There are measures as follows:

\subsubsection{Introduction of advanced agricultural technology and concept}

The grain output in northwest and southwest regions of Sichuan is not high due to the landform features of hills; however, those regions plant fresh fruits such as oranges, kiwi fruits, and lemons with high nutritional value but difficulty in preservation. Thus, it is a good way to introduce advanced technology to process various agricultural products to subsidiary agricultural products, which can both extract their nutritional value and increase benefits for farmers. Moreover, "contract farming" is also a practical way by opening a green channel for farmers to relieve their pressure and guarantee their income.

\subsubsection{Improvement of rural infrastructure construction}

In the northwest and southwest regions, the supporting agricultural facilities are backward, the rural power network is incomplete, and the agricultural mechanization level is relatively low. Thus, basing on agriculture and taking agriculture-oriented measures, the government has to take advantage of scientific and technological progresses to strengthen construction and transformation of rural power network, improve popularity level of electric energy, and enhance electricity consumption conditions in rural 


\section{REFERENCES}

areas. In the meanwhile, it should introduce advanced agricultural machinery at home and abroad as well as improving level of machinery equipment and mechanical skills. The government should also provide more financial support by enhancing such supporting policies as subsidies for purchasing machinery and fuel subsidies so as to improve level of agricultural mechanization [6].

\subsubsection{Development of agriculture with unique characteristics in minority regions}

There are multiple ethnic minorities in Sichuan province, and they have the potential of selecting, developing, and creating one or two national and even international bases of characteristic agricultural products with a view to the production conditions, resource endowments, and ecological conditions in the regions. Besides, the minority regions of Sichuan are rich in unique world-level ecotourism resources. Therefore, it is an inevitable choice of the minority regions of Sichuan to develop characteristic agriculture to strengthen comparative advantages of their unique agricultural products, relying on the agglomeration, decentralized functions and brand effects of tourism to enhance competitiveness, to increase product market share and added value [7]. As a result, it is beneficial to transform abundant resource advantages to industrial strengths so as to overcome the disadvantages of locations and transform the inferiority to superiority and finally walk out of the dilemma on the brink.

\section{ACKNOWLEDGMENTS}

Correspongding Author: guozhu. He,Sichuan Agricultural University.
[1] Yu Yan. Factors influencing comprehensive agricultural production capacity in reclamation area of heilongjiang province $[\mathrm{J}]$. China agricultural accounting,2012(05):42-43.

[2] Chaode Yan, Hongan Xiao. Grey Relation Analysis of the Influencing Factors on Agricultural Synthesis Productivity in Henan Province. Journal of Anhui Agricultural Sciences. 2011, 39(35): 22079-22081, 22084.

[3] Peng jing. Research on plateau characteristic leisure agriculture development in sichuan province [J]. Jiangxi agriculture 2019, (16): 49+55.

[4] Chen mingshu. Application of grey analysis method in optimizing the structure of planting industry in chongqing $[\mathrm{J}]$. Modern agricultural science and technology, 2017(20): 53-54.

[5] Rengui Zhang. Grey Correlation Degree Analysis on Agricultural Productivity of in Jiangsu Province. Journal of Hebei Agricultural Sciences, 2009, 13 (03): 104-107.

[6] Liu li. Strategies and paths of rural revitalization in minority areas under the new situation [J]. Journal of three gorges university,2019, 41(04):52-58.

[7] Shi Wang. Two Examples of the Characteristic Agricultural Development in the Ethnic Minority Regions of Sichuan Province. Rural Economy, 2012, (06). 